\title{
Waste ostrich- and chicken-eggshells as heterogeneous base catalyst for biodiesel production from used cooking oil: catalyst characterization and biodiesel yield performance
}

\begin{abstract}
The primary goal of this paper is to investigate the catalyst characterization and biodiesel yield of a bio-diesel converted from a used cooking oil source via heterogeneous catalysts derived from very rare type of eggshell: ostrich-eggshell (ostrich-eggshell derived $\mathrm{CaO}$ ). It also aims to compare the performance of $\mathrm{CaO}$ catalyst derived from both waste ostricheggshell and the conventional chicken-eggshell, and to find the optimum conditions for biodiesel production. The prepared catalysts were then characterized by using XRD, FT-IR, BET, SEM, TGA and CO2-TPD. The parametric effects on the biodiesel production, such as catalyst concentration, molar ratio of methanol to oil, reaction temperature, reaction time, speed and reusability of the catalyst were investigated. The experimental result showed that 1.5 wt. \% catalyst, $12: 1 \mathrm{M}$ ratio of methanol to oil, $65^{\circ} \mathrm{C}$ reaction temperature, $2 \mathrm{~h}$ reaction time with speed of $250 \mathrm{rpm}$ gave the best results. It was found that the ostrich-eggshell derived $\mathrm{CaO}$ catalyst shows higher surface area,higher basicity and smaller particle size. The maximum biodiesel yield is $96 \%$ and $94 \%$ for calcined ostrich-eggshell and chicken-eggshell, respectively. The $\mathrm{CaO}$ catalyst derived from waste calcined ostrich and chicken-eggshell maintained a good catalytic activity even after being repeatedly used for 5 cycles with yield around $70 \%$, which implies potential saving and affordable biodiesel production possibilities.
\end{abstract}

Keyword: Biodiesel production; Waste cooking oil; Ostrich-eggshell; Chicken-eggshell; Heterogeneous catalyst; Transesterification 